OPEN ACCESS

Edited by:

Xin-Hao Li

Shanghai Jiao Tong University, China

Reviewed by:

Xiaogin Zou,

Northeast Normal University, China

Mustafa Ersoz,

Selçuk University, Turkey

${ }^{*}$ Correspondence:

Yangxue $L$

yangxueli@jlu.edu.cn

Specialty section:

This article was submitted to

Colloidal Materials and Interfaces,

a section of the journal

Frontiers in Materials

Received: 13 September 2018

Accepted: 25 January 2019

Published: 19 February 2019

Citation:

Guan H, Zou D, Yu H, Liu M, Liu Z,

Sun W, XU F and Li Y (2019)

Adsorption Behavior of lodine by Novel Covalent Organic Polymers

Constructed Through Heterostructural Mixed Linkers. Front. Mater. 6:12. doi: 10.3389/fmats.2019.00012

\section{Adsorption Behavior of lodine by Novel Covalent Organic Polymers Constructed Through Heterostructural Mixed Linkers}

\author{
Heda Guan ${ }^{1}$, Donglei Zou ${ }^{1}$, Haiyang Yu ${ }^{1}$, Meijun Liu ${ }^{1}$, Zhi Liu ${ }^{2}$, Wentian Sun ${ }^{1}$, Feifan Xu ${ }^{1}$ \\ and Yangxue $L i^{1,3,4 *}$ \\ ${ }^{1}$ Key Lab of Groundwater Resources and Environment, Ministry of Education, Jilin University, Changchun, China, ${ }^{2}$ School of \\ Municipal and Environmental Engineering, Jilin Jianzhu University, Changchun, China, ${ }^{3}$ State Key Laboratory of Inorganic \\ Synthesis and Preparative Chemistry, College of Chemistry, Jilin University, Changchun, China, ${ }^{4}$ State Key Laboratory of \\ Superhard Materials, Jilin University, Changchun, China
}

The efficient capture and storage radioactive iodine $\left({ }^{129} \mid\right.$ or $\left.{ }^{131} \mid\right)$ formed during the extensive use of nuclear energy is of paramount importance. Therefore, it is a great deal to design and empolder new adsorbents for effectively disposing of iodine from nuclear waste. In this work, we presented a novel covalent organic polymer (JLUE-COP-3) constructed through heterostructural mixed linkers with perforated porousness, plenty of $\pi$-conjugated phenyl rings and functional $-\mathrm{CO}-\mathrm{NH}-$ and $-\mathrm{SO}_{3} \mathrm{H}$ groups to iodine adsorption process. After fully characterizing the morphology and structure, the adsorption behavior of iodine by the resultant polymers were explored in detail. The external adsorption behavior was determined to obey the pseudo-second order kinetic model according to the kinetic analysis. The maximum liquid adsorption capacity was obtained to reach $153.85 \mathrm{mg} / \mathrm{g}$ at $298 \mathrm{~K}$, which was evaluated by the Langmuir isotherm model. In addition, the negative attributes of $\Delta G^{\circ}$ as well as the positive attributes of $\Delta H^{\circ}$ and $\Delta S^{\circ}$ at three temperatures indicated the nature of the iodine adsorption over JLUE-COP-3 was spontaneous and endothermic. The current study could look forward to making great contributions to the facile fabrication of late-model three-component POP materials and their applications in treatment of nuclear waste.

Keywords: covalent organic polymers, iodine, adsorption, kinetic analysis, thermodynamic analysis

\section{INTRODUCTION}

Nowadays, as the energy demand in the world becoming increasingly tense and the environment getting worse day by day, nuclear energy is more and more in people's graces. Or, at all events, with one drawback that radioactive waste including ${ }^{14} \mathrm{CO}_{2},{ }^{85} \mathrm{Kr},{ }^{3} \mathrm{H}, \mathrm{I}^{123}$, I ${ }^{125}$, and I ${ }^{127-140}$, would be produced when nuclear fuel fission occurs (Ma et al., 2016). Radioactive iodine is considered as one of the most dangerous radioactive elements with the characteristics of long half-life and large heat release, which is difficult to change using any conventional method. In view of the threat to human health and the cause of mutant plants and animals, it still requires seeking out more efficient and longer-term solutions to address the capture and storage of radioactive iodine isotopes (Kosaka et al., 2012; Qian et al., 2016; Lin Y. et al., 2017). So far, with the growing popularity of effective and low-cost adsorption technology, various porous adsorbents have been tested for 


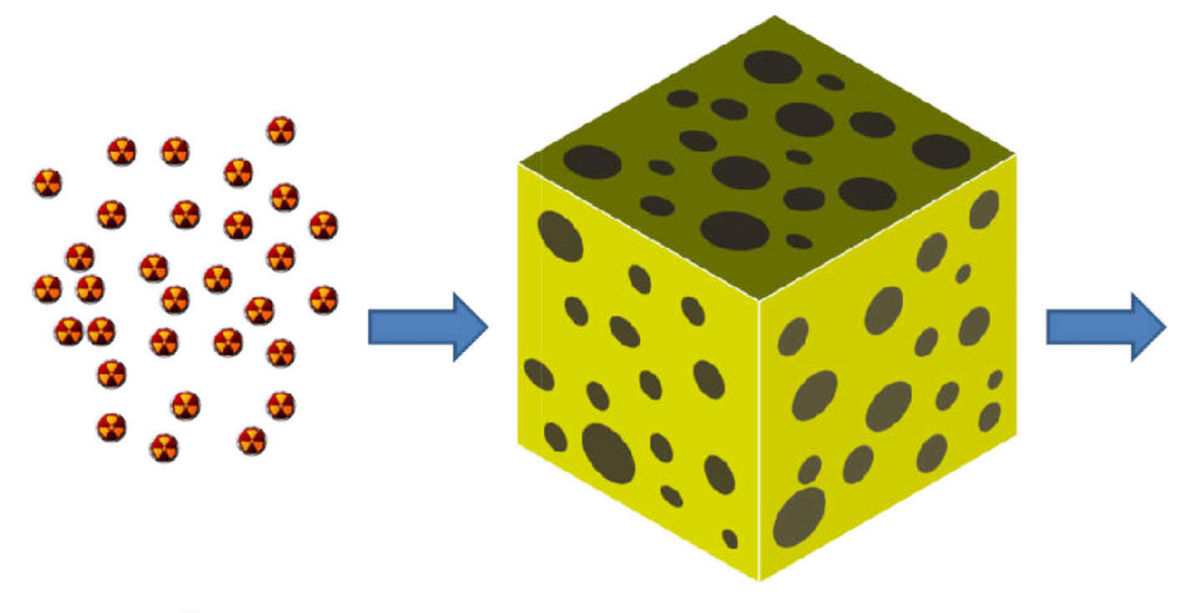

$\mathbf{I}_{2}$

JLUE-COP-3



I @ JLUE-COP-3

SCHEME 1 | Schematic illustration of the iodine adsorption over the developed adsorbent of JLUE-COP-3.

handling iodine pollution, containing silica gel, porous organic cages, activated carbon, and zeolites, etc. (Hasell et al., 2011; Ali, 2012; Azadbakht et al., 2016; Li et al., 2016; Zhang et al., 2017; Janeta et al., 2018). However, the low adsorption capacity associate with easy-lost activity render the adsorbents with some shortcomings (Sigen et al., 2014). Hence, developing qualified adsorbents with high adsorption capacity, low cost and strong adaptability to make up for insufficient remains a challenge.

Porous organic polymers (POPs), as a rising kind of porous material, which usually formed from covalent condensation of two organic building units, have sprang up rapidly as a new type of solid adsorbent by virtue of permanent porosity, tailored pore sizes, designable structures, and adsorption sites (Calik et al., 2016; Sun et al., 2017a; Yang H. S et al., 2017; Yuan et al., 2018). There can be no doubt that the POPs fulfill all the needs as an eligible adsorbent for removing specific contaminant from water (Ding et al., 2016; Sun et al., 2017b). In recent years, POPs have been turned out the validity and feasibility of the appropriateness for solving environmental issues beyond their previous application in catalysis aspect, molecular recognition field and so on and so forth (Huang et al., 2017). Of particular success are the utilization to decontaminate various toxic and hazardous substances involving heavy metal ions and organic pollutants, of course, certainly with the efficient volatile iodine removal (Liao et al., 2016; Lin L. et al., 2017; Merí-Bof et al., 2017; Guo et al., 2018).

Despite the great progresses have been made in the past, the structural variability of POPs in contrast to metal-organic frameworks (MOFs) are quite astricted on account of the limitation of synthetic methods and constitutional units. Thus, the great goal of expanding the family of POPs are highly soughtafter by the researchers (Chen et al., 2015; Zeng et al., 2015; Pang et al., 2016). Among which, both Jiang's group and Zhao's group have done pioneering work in aforementioned respect. Strongly motivated by the heterostructural mixed linker approach, our group have developed two three-component COPs (JLUE-COP1 and JLUE-COP-2) for removing cationic dyes from wastewater (Dong et al., 2018). Herein, as an extension and expansion of the previous work, we exploited JLUE-COP-3 with benzene1,3,5-tricarbohydrazide (BTCH), 4,4'-biphenyldicarboxaldehyde (BPDA), and 2,5-diaminobenzenesulfonic acid (DABA) through a simple and high-speed Schiff base chemistry using DMSO as solvent (Scheme 2). The three-component JLUE-COP-3 was endowed with perpetual porosity, plenty of $\pi$-conjugated phenyl rings and functional $-\mathrm{CO}-\mathrm{NH}-$ and $-\mathrm{SO}_{3} \mathrm{H}$ groups. The assynthesized JLUE-COP-3 was characterized by powder X-ray diffraction (PXRD), fourier transform infrared spectra (FT-IR), thermogravimetric analysis (TGA) and so on. Judging from the characteristics of perforated porousness, introduction of electron-rich heteroatoms as well as $\pi$-conjugated networks, which are in favor of improving the affinity between JLUECOPs and iodine molecules, we adopted the JLUE-COP-3 as an efficient adsorbent for the adsorption of iodine (Scheme 1). Furthermore, the adsorption kinetics, adsorption isotherms, and thermodynamics of iodine over the JLUE-COP-3 were studied. The JLUE-COP-3 for iodine adsorption represented remarkable three advantages: (1) easy accessibility, (2) multiple functionality, and (3) good reusability. This study not only straightens out extending late-model POP materials detached from the original two-component pattern, but also lays the foundation for the functionalized POPs applying in remediation of radioactive iodine.

\section{EXPERIMENTAL SECTION}

\section{Materials}

All starting reagents, except benzene-1,3,5-tricarbohydrazide, were purchased commercially and used directly as received without further purification (Dong et al., 2018). 


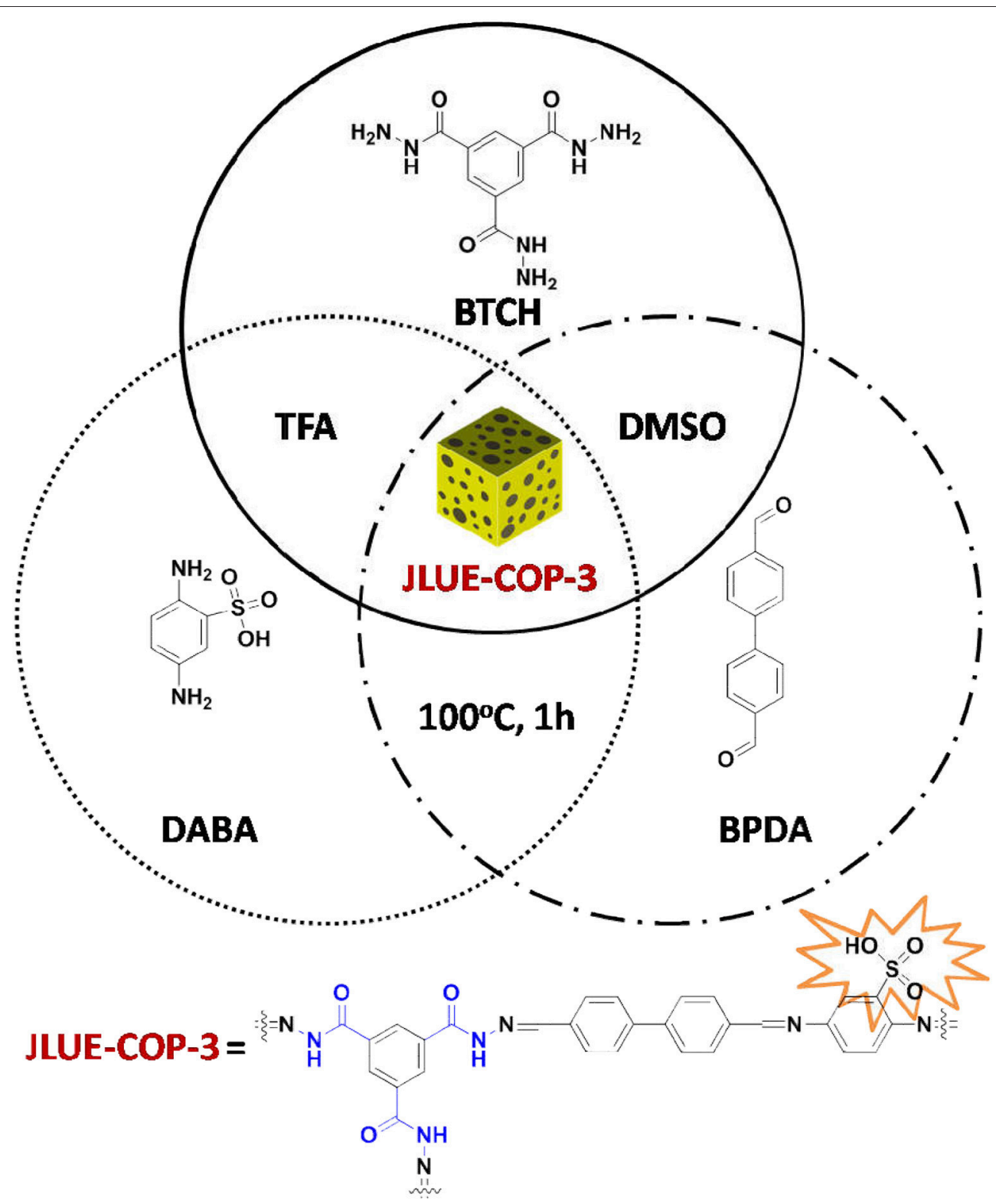

SCHEME 2 | The synthesized producer of JLUE-COP-3.

\section{Instruments and Characterization}

The morphology of the JLUE-COP-3 was probed by Fieldscanning electron microscopy (FE-SEM, JEOLJXA-840, $15 \mathrm{kV}$ ). The powder X-ray diffraction (PXRD) spectrum of JLUE-COP3 was performed by a Riguku D/MAX2550 diffractometer using $\mathrm{CuK \alpha}$ radiation, $40 \mathrm{kV}, 200 \mathrm{~mA}$ with scanning rate of $4 \% \mathrm{~min}$. The X-ray photoelectron spectroscopy (XPS) was conducted on a ESCALAB 250Xi X-ray photoelectron spectroscopy. The fourier transform infrared spectrum (FT-IR) of JLUE-COP-3 was measured on a Nicolet Nexus 410 infrared spectrometer spectrum instrument using the $\mathrm{KBr}$ method ranging from 4,000 to $400 \mathrm{~cm}^{-1}$. The thermogravimetric analysis (TGA) was recorded by heating the JLUE-COP-3 at a rate of $10^{\circ} \mathrm{C} / \mathrm{min}$ in nitrogen flow. The optical absorption spectra were recorded using UV-Vis spectrophotometer (Varian Cary 3 Bio, Australia).

\section{Synthesis of JLUE-COP-3}

A mixture of benzene-1,3,5-tricarbohydrazide (BTCH, 0.2 mmol, $0.05 \mathrm{~g}$ ), 4,4'-biphenyldicarboxaldehyde (BPDA, $0.6 \mathrm{mmol}$, $0.13 \mathrm{~g}$ ), 2,5-diaminobenzenesulfonic acid (DABA, $0.3 \mathrm{mmol}$, $0.056 \mathrm{~g}$ ) and $\mathrm{CF}_{3} \mathrm{COOH}$ (TFA, 2d) in a solution of dimethyl sulphoxide (DMSO, $10 \mathrm{~mL}$ ) were heated at $100^{\circ} \mathrm{C}$ for $1 \mathrm{~h}$. Afterwards, a dark brown product (JLUE-COP-3) was afforded in $95 \%$ yield. Elemental analysis (wt.\%) calcd. For $\left\{\mathrm{C}_{32} \mathrm{H}_{23} \mathrm{~N}_{8} \mathrm{O}_{6} \mathrm{~S}\right\} \mathrm{n}$ : C 59.35, H 3.55, N 17.31; found: C 59.83, H 3.53, N 17.85. 


\section{Adsorption of lodine}

Adsorption of iodine over the JLUE-COP-3 was conducted with batch experiments as follows: (i) the JLUE-COPs $(10 \mathrm{mg})$ were placed into a sealed vessel filled with iodine/hexane solution (50$300 \mathrm{mg} / \mathrm{L}, 10 \mathrm{~mL}$ ) and held for a period of time; (ii) then the absorbance of supernatant in the anterior vessel was measured at a wavelength of $525 \mathrm{~nm}$ by UV-vis at various time intervals.

The removal efficiency $(E, \%)$ as well as the iodine adsorbed amount $q_{e}(\mathrm{mg} / \mathrm{g})$ were calculated using the following equations (Duan and Su, 2014):

$$
\begin{array}{r}
q_{e}=\frac{\left(C_{0}-C_{e}\right) V}{m} \\
E(\%)=\frac{C_{0}-C_{e}}{C_{0}} \times 100 \%
\end{array}
$$

Where $C_{0}$ and $C_{e}$ are the initial iodine concentration and equilibrium iodine concentration $(\mathrm{mg} / \mathrm{L})$, respectively; $m$ is the quality of JLUE-COP-3 used $(\mathrm{g}) ; \quad V$ is the dosage of solution used (L).

\section{RESULTS AND DISCUSSION}

SEM images showed that JLUE-COP-3 has a bowl-shaped structure containing of nanoparticles (Figures 1A-C). As the Figure 1D shows, the EDS spectrum of the JLUE-COP-3 also pointed the expected constituents of $\mathrm{C}, \mathrm{N}, \mathrm{O}$, and $\mathrm{S}$. The XPS spectrum of JLUE-COP-3 was displayed in Figure 2A. The peaks at $288-283.1 \mathrm{eV}$ of $\mathrm{C} 1 \mathrm{~s}$, indicated the presence of $\mathrm{C}-\mathrm{C}, \mathrm{C}-$ $\mathrm{H}, \mathrm{C}=\mathrm{C}$ and $\mathrm{C}=\mathrm{O}$, etc. in the skeleton; whereas the peaks at $530-532 \mathrm{eV}$ of $\mathrm{O} 1 \mathrm{~s}, 399-401 \mathrm{eV}$ of $\mathrm{N} 1 \mathrm{~s}$, and $166-169 \mathrm{eV}$ of $\mathrm{S} 2 \mathrm{p}$, further confirmed the being of $-\mathrm{CO}-\mathrm{NH}-$ and $-\mathrm{SO}_{3} \mathrm{H}$ on the polymer (Dimos et al., 2017). To gain further insights into the chemical structure of JLUE-COP-3, FT-IR spectrum was performed. Obviously, in JLUE-COP-3 material, the peaks located at around 1,632 and $1,074 \mathrm{~cm}^{-1}$, the respective indicator of imine $v_{\mathrm{C}=\mathrm{N}}$ stretching vibration and $\mathrm{O}=\mathrm{S}=\mathrm{O}$ stretching band, implying the solid evidence for the successful synthesis of JLUECOP-3 (Figure 2B). The PXRD pattern of JLUE-COP-3 matched with the amorphous property, which might be attributed to the incapable of offering error correction due to the quick forming process (Nguyen and Grunwald, 2018) (Figure 2C). To investigate the thermal and chemical stabilities of JLUE-COP-3, thermogravimetric analysis (TGA) was adopted under a nitrogen flow. As presented in Figure 2D, the TGA profile of JLUECOP-3 demonstrated the high thermal stability up to $320^{\circ} \mathrm{C}$. The permanent porous feature of JLUE-COP-3 was estimated by $\mathrm{N}_{2}$ adsorption-desorption measurement at $77 \mathrm{~K}$ (Figure 3). The sorption isotherm represent a IV type with a Brunauer-EmmetTeller surface area of $46 \mathrm{~m}^{2} / \mathrm{g}$ and Langmuir surface area of 72 $\mathrm{m}^{2} / \mathrm{g}$, providing a combination of micro- and meso-pores in the structure of JLUE-COP-3.

As known to all, long contact time and high initial concentrations were propitious to the adsorption amount. To corroborate the above arguments, batch experiments were
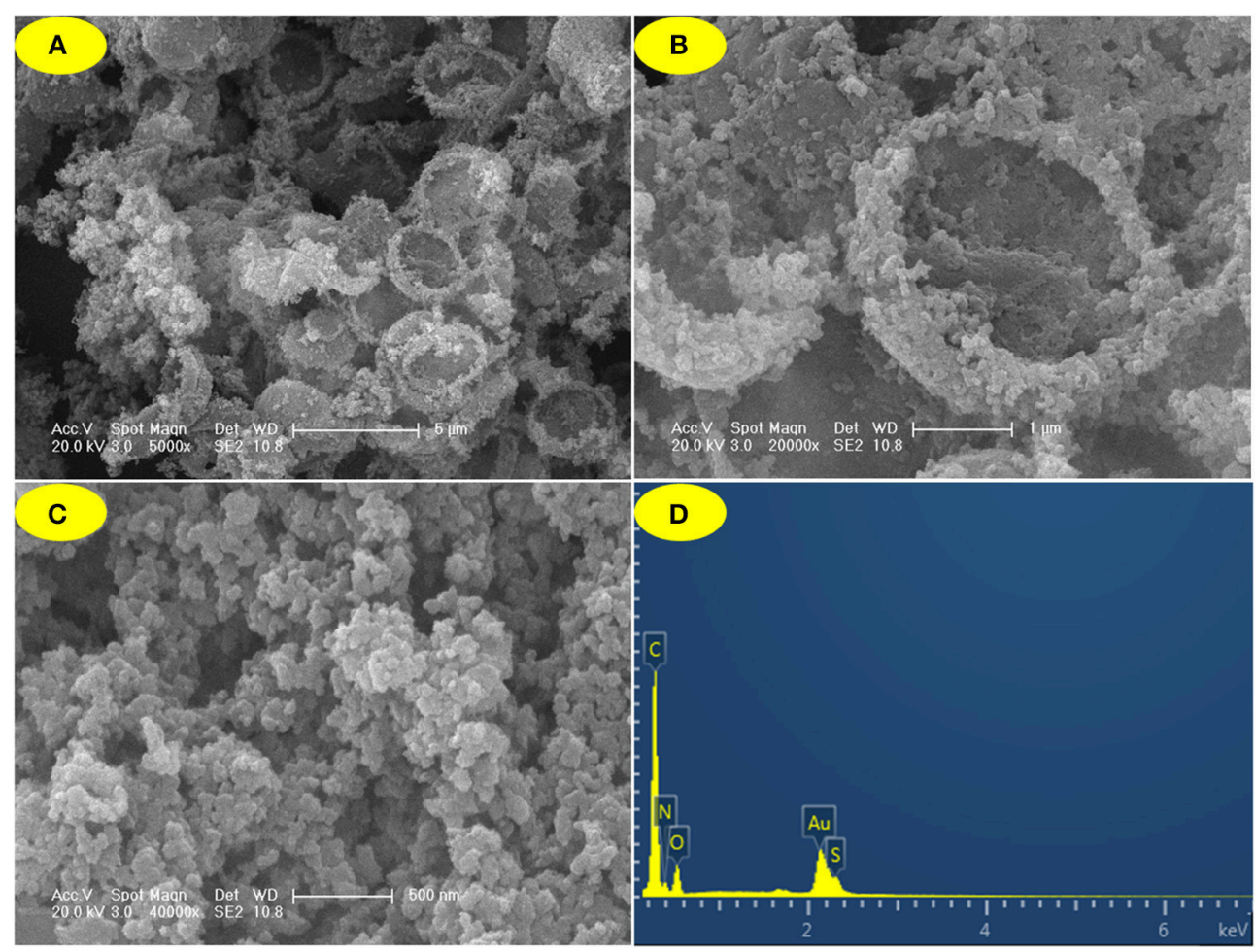

FIGURE 1 | (A-C) SEM images of JLUE-COP-3. (D) EDS spectrum of JLUE-COP-3. 

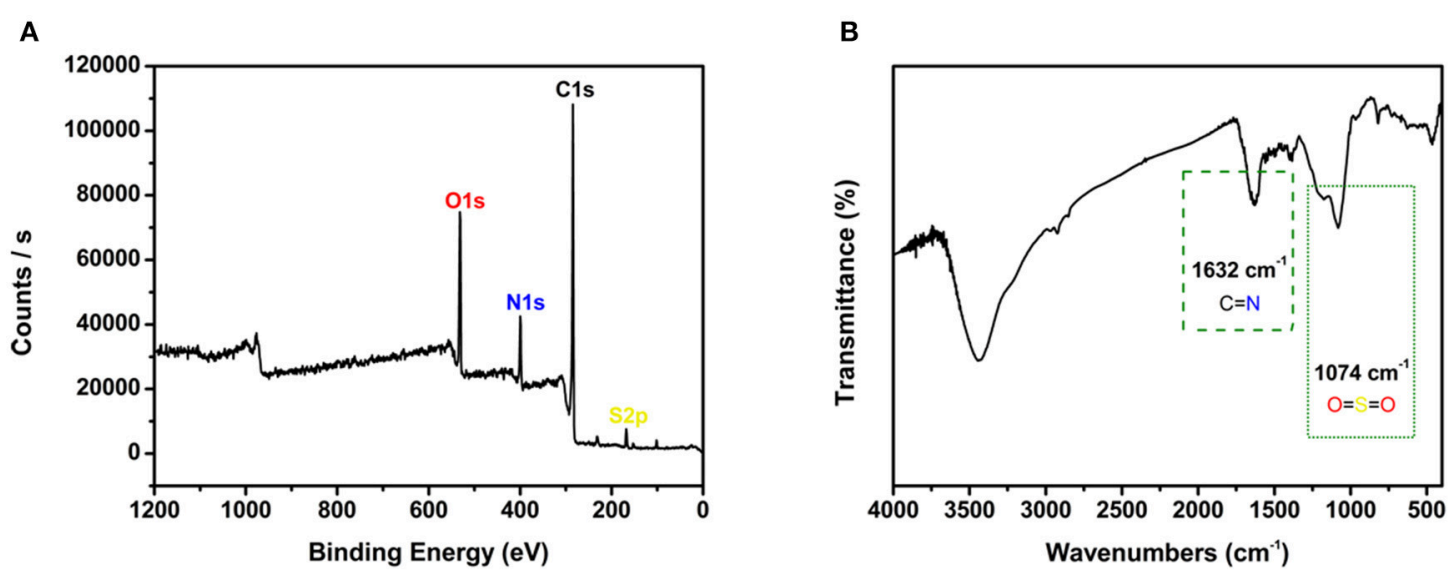

C
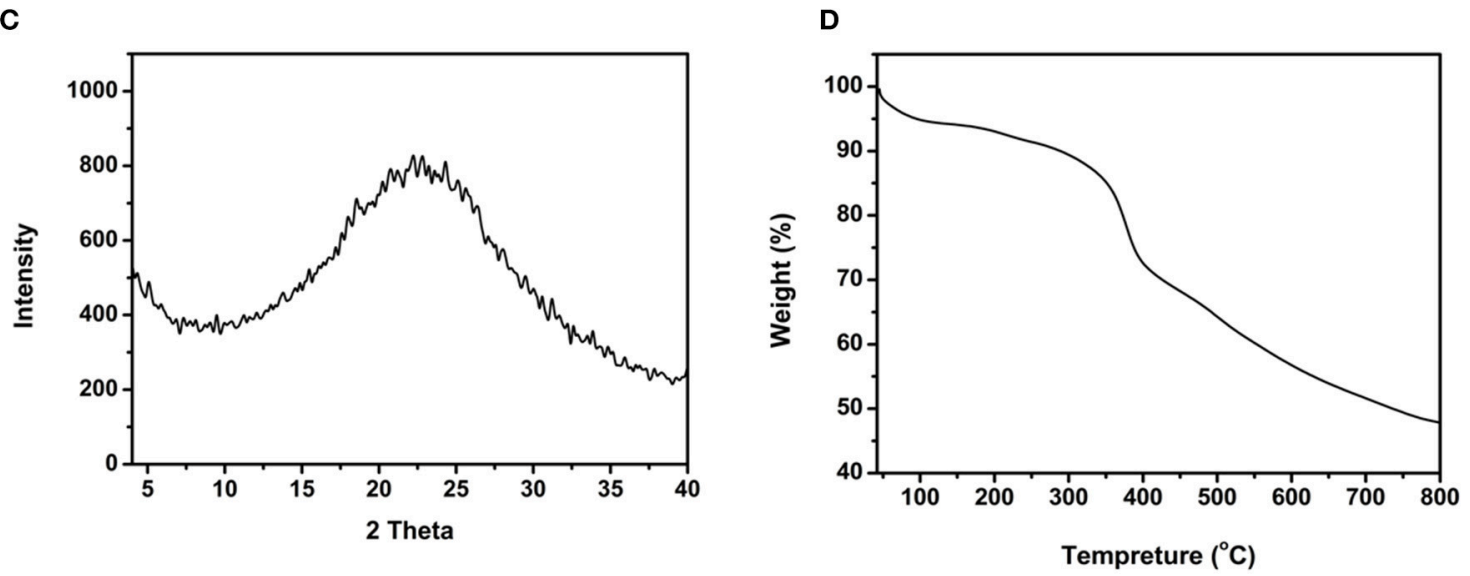

FIGURE 2 | (A) XPS spectrum of JLUE-COP-3. (B) FT-IR spectrum of JLUE-COP-3. (C) PXRD spectrum of JLUE-COP-3. (D) TGA curve of JLUE-COP-3.
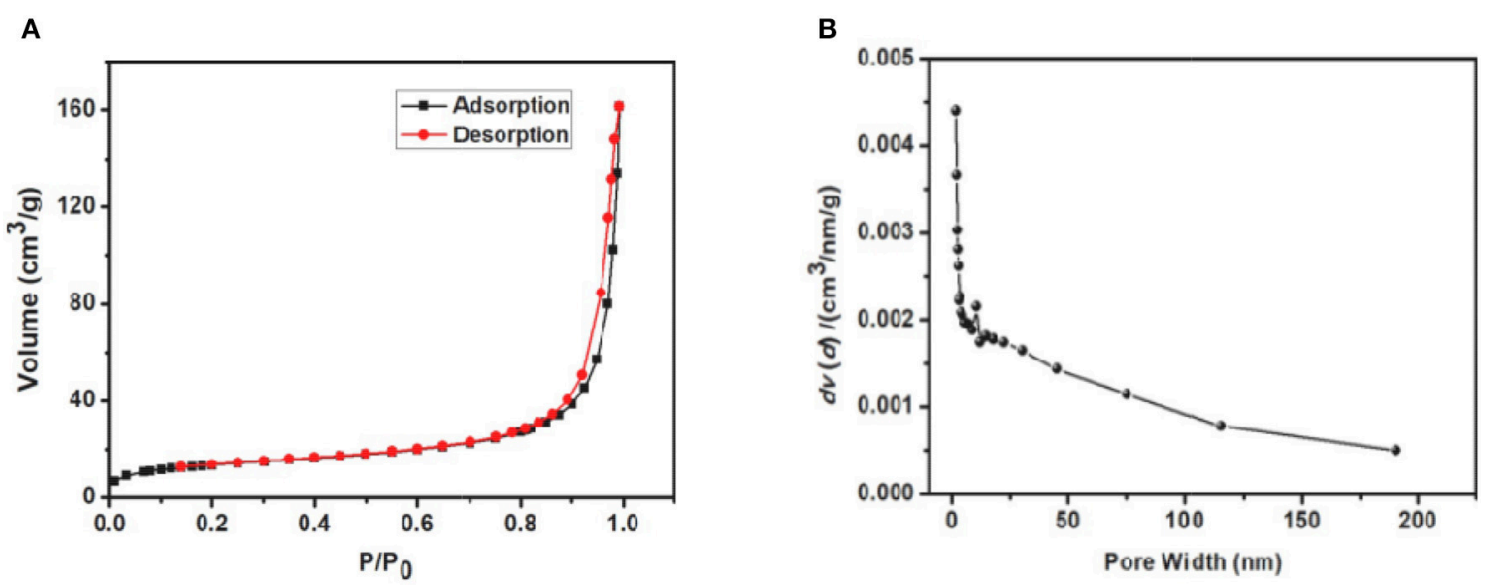

FIGURE 3 | (A) Nitrogen adsorption and desorption isotherms of JLUE-COP-3 measured at $77 \mathrm{~K}$ and (B) pore size distribution of JLUE-COP-3.

conducted at room temperature. As shown in Figure 4A, at first, a substantial number of active sites were exposed on the surface of JLUE-COP-3, the adsorption rate sharply rised in the first $24 \mathrm{~h}$; with the passage of time, the active sites and the pores were gradually occupied and blocked, the adsorption rate slowly paced down from 24 to $96 \mathrm{~h}$; finally, the saturation of iodine adsorption over JLUE-COP-3 reached at $120 \mathrm{~h}$. Furthermore, when the initial concentration varied from 100 to $300 \mathrm{mg} / \mathrm{L}$, the corresponding 


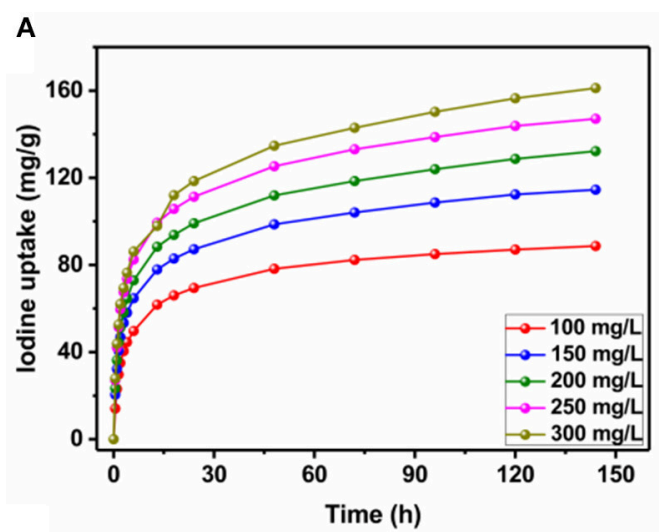

C

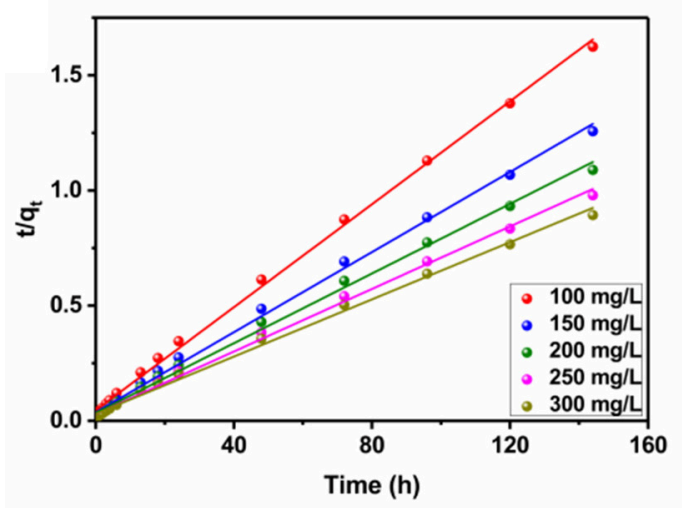

B

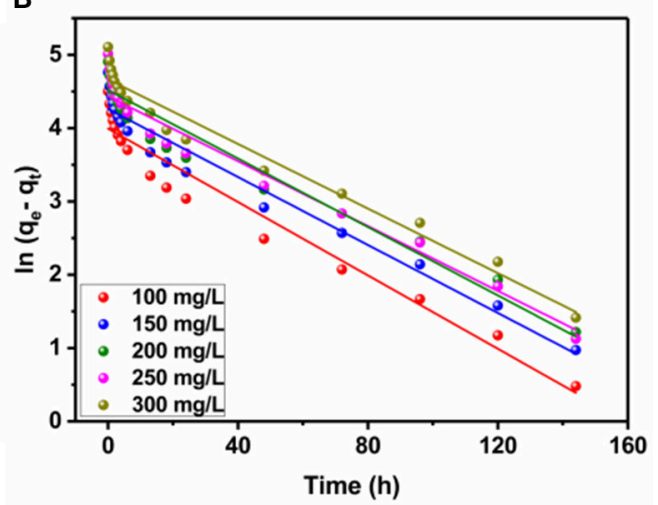

D

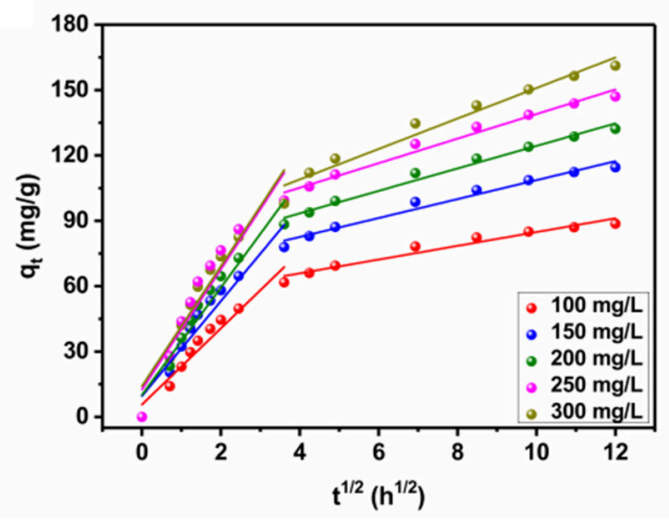

FIGURE 4 | (A) Kinetics of iodine adsorption over JLUE-COP-3 at different concentrations (100-300 mg/L) at T = 298 K. (B) Pseudo-first-order curve-fittings. (C) Pseudo-second-order curve-fittings. (D) Intraparticle diffusion models for iodine adsorption over JLUE-COP-3 at different initial iodine concentrations.

TABLE 1 | Kinetic parameters of iodine adsorption over JLUE-COP-3.

\begin{tabular}{|c|c|c|c|c|c|c|c|c|}
\hline $\begin{array}{l}C_{0} \\
\text { (mg/L) }\end{array}$ & $\begin{array}{c}q_{\exp } \\
(\mathrm{mg} / \mathrm{g})\end{array}$ & $\begin{array}{c}\text { Removal } \\
\text { efficiency } \\
(\%)\end{array}$ & \multicolumn{3}{|c|}{ Pseudo-first order kinetic } & \multicolumn{3}{|c|}{ Pseudo-second order kinetic } \\
\hline 100 & 90.29 & 90.29 & 0.025 & 54.26 & 0.95 & 0.0025 & 90.91 & 0.99 \\
\hline 150 & 117.21 & 78.14 & 0.023 & 70.91 & 0.96 & 0.0018 & 117.65 & 0.99 \\
\hline 200 & 135.59 & 67.80 & 0.021 & 84.28 & 0.95 & 0.0015 & 135.14 & 0.99 \\
\hline
\end{tabular}

maximum adsorption amounts and removal efficiencies of iodine over JLUE-COP-3 were $90.29 \mathrm{mg} / \mathrm{g} \& 90.29 \%, 117.21 \mathrm{mg} / \mathrm{g} \&$ $78.14 \%, 135.59 \mathrm{mg} / \mathrm{g} \& 67.80 \%$ and $150.15 \mathrm{mg} / \mathrm{g} \& 60.06 \%$, $165.29 \mathrm{mg} / \mathrm{g} \& 55.10 \%$, respectively. This phenomenon could be explained as: the increased initial concentration of iodine produced the raising of effective collision probability between JLUE-COP-3 and iodine, thus resulting in the improvement of the adsorption amount; on the other hand, the dropped removal efficiency could be put down to the supersaturated adsorption sites relative to the larger amounts of iodine. In brief, the efficient iodine adsorption performance of JLUE-COP-3 can be summed up in three points: (a) the porous specific may be beneficial to the transport of iodine molecules in the adsorption process; (b) the abundant $\pi$-conjugated phenyl rings could enhance the affinity between the JLUE-COP-3 and iodine molecules; and (c) the framework incorporated with electron-rich heteroatoms may strengthen the iodine enrichment behavior of JLUE-COP-3.

The adsorption kinetic study could depict the adsorption rate of controlling the equilibrium time of the adsorption process. In order to understand the innate character of iodine-JLUE-COP-3 interactions, the experimental data were evaluated by the kinetic models of first and second order models, even intraparticle 
diffusion model, which can be expressed as following equations (Ho and McKay, 1999; Duan et al., 2015; Dong et al., 2018):

$$
\begin{aligned}
\ln \left(q_{e}-q_{t}\right) & =\ln q_{e}-k_{1} t \\
\frac{t}{q_{t}} & =\frac{1}{k_{2} q_{e}^{2}}+\frac{t}{q_{e}}
\end{aligned}
$$

TABLE 2 | Intraparticle diffusion model parameters for the adsorption of iodine

\begin{tabular}{|c|c|c|c|c|c|c|}
\hline \multirow{2}{*}{$\begin{array}{l}C_{0} \\
(\mathrm{mg} / \mathrm{L})\end{array}$} & \multicolumn{6}{|c|}{ Intraparticle diffusion model } \\
\hline & \multicolumn{2}{|c|}{$\left(\mathrm{mg} / \mathrm{g} / \mathrm{h}^{1 / 2}\right)(\mathrm{mg} / \mathrm{g})$} & $R^{2}$ & $\begin{array}{c}k_{i, 2} \\
(\mathrm{mg} / \mathrm{g} / \mathrm{l}\end{array}$ & $\begin{array}{c}C_{2} \\
(\mathrm{mg} / \mathrm{g})\end{array}$ & $R^{2}$ \\
\hline 100 & 17.49 & 5.69 & 0.94 & 3.16 & 53.28 & 0.96 \\
\hline 150 & 21.76 & 9.65 & 0.92 & 4.34 & 65.24 & 0.98 \\
\hline 200 & 24.63 & 10.14 & 0.94 & 5.16 & 72.81 & 0.98 \\
\hline 250 & 27.59 & 12.60 & 0.93 & 5.63 & 82.67 & 0.98 \\
\hline 300 & 27.50 & 14.20 & 0.90 & 6.99 & 81.04 & 0.96 \\
\hline
\end{tabular}
over JLUE-COP-3.

$$
q_{t}=k_{i} t^{1 / 2}+C
$$

Where $q_{t}$ and $q_{e}$ are the iodine adsorbed amounts at time $t$ and equilibrium $(\mathrm{mg} / \mathrm{g})$, respectively; $k_{1}$ is the pseudo-first-order model rate constant $(1 / \mathrm{h})$, and $k_{2}$ is the pseudo-second-order rate constant $(\mathrm{g} / \mathrm{mg} / \mathrm{h})$, respectively; $k_{i}$ is the intraparticle diffusion rate constant $\left(\mathrm{mg} / \mathrm{g} / \mathrm{h}^{1 / 2}\right)$, and $C$ is the intercept $(\mathrm{mg} / \mathrm{g})$.

Adsorption kinetics of iodine on JLUE-COP-3 along with the as-fitted parameters using the pseudo-first-order and pseudo-second-order models are presented in Figures 4B,C and tabulated in Table 1, respectively. For all five concentration gradients, originating from the quite higher coefficient values of $R^{2}$ (all above 0.99 ) and more consistent practical values of $q_{\text {exp }}$, the pseudo-second-order kinetic model, which is used to describe the chemisorption-type process, correlates the kinetic data effectively. This result is in keeping with the existence of strong interactions between the JLUE-COP-3 and the iodine molecules. More concretely, the inherent - $\mathrm{CO}-\mathrm{NH}-$ and $\mathrm{SO}_{3} \mathrm{H}$ moieties besides connatural aromatic ring in the polymer skeleton, which could work as electron donor, while the iodine could act as electron acceptor. Thereupon then, the chargetransfer (CT) interactions between the electron donor and
A

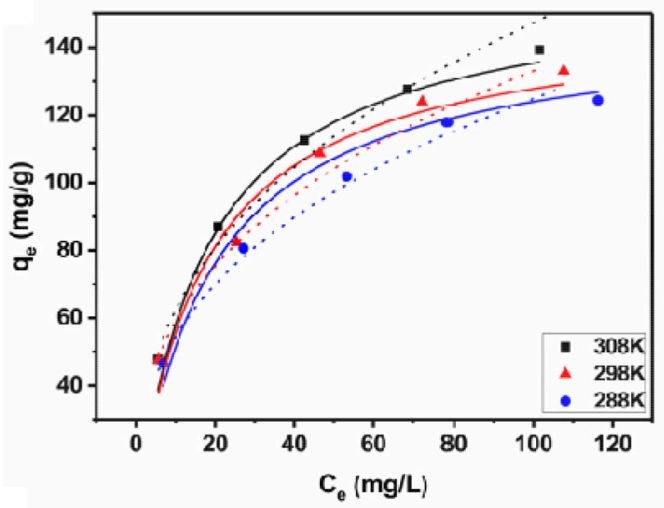

C

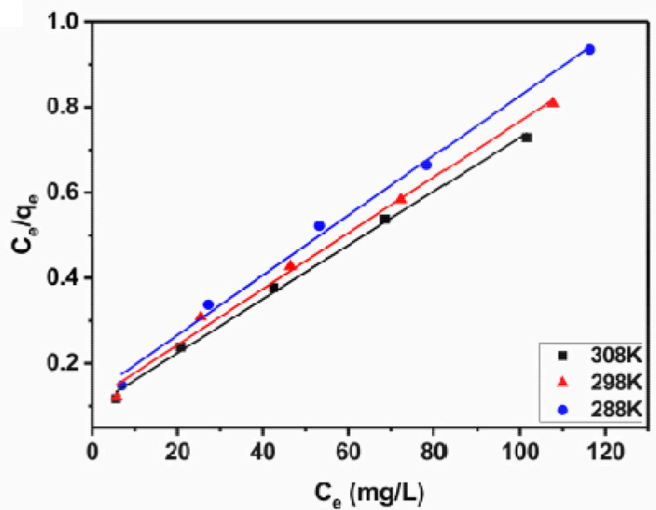

B

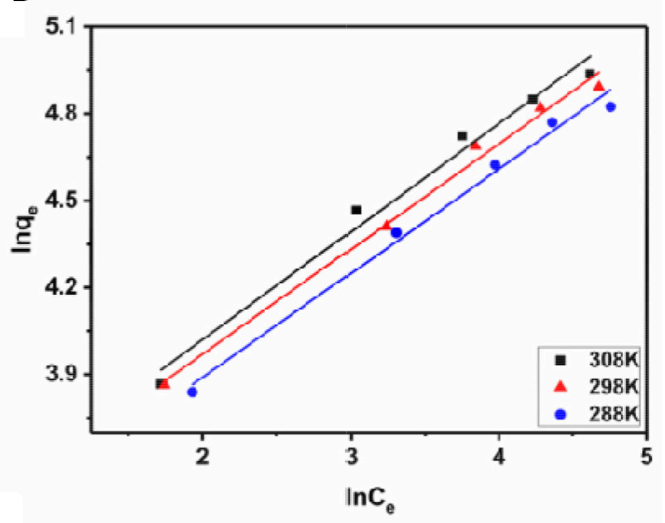

D

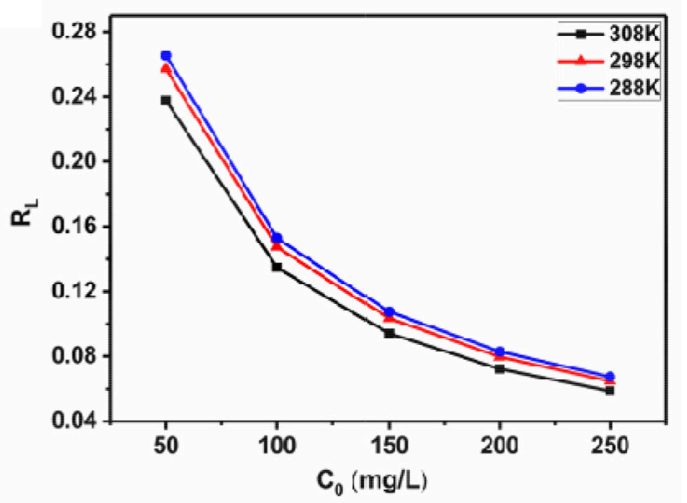

FIGURE 5 | (A) Data fittings with Langmuir and Freundlich adsorption isotherms of iodine adsorption over JLUE-COP-3 at different temperatures (288, 298, and 308 K); solid lines: Langmuir model, dashed lines: Freundlich model. (B,C) are the Langmuir and Freundlich linear fittings for the iodine adsorption over JLUE-COP-3, respectively. (D) Separation factors for iodine adsorption over JLUE-COP-3. 
TABLE 3 | Langmuir isotherm parameters for iodine adsorption over JLUE-COP-3.

\begin{tabular}{llcccc}
\hline $\begin{array}{l}\text { Langmuir } \\
\text { isotherm }\end{array}$ & Temperature (K) & $\boldsymbol{Q}_{\boldsymbol{m}}$ & $\boldsymbol{K}_{\boldsymbol{L}}$ & $\boldsymbol{R}^{\mathbf{2}}$ & $\boldsymbol{R}_{\boldsymbol{L}}$ \\
\hline $\mathrm{L}$ & $288 \mathrm{~K}$ & 142.86 & 7.91 & 0.99 & $0.067 \sim 0.265$ \\
& $298 \mathrm{~K}$ & 153.85 & 8.89 & 0.99 & $0.065 \sim 0.257$ \\
& $308 \mathrm{~K}$ & 158.73 & 10.18 & 0.99 & $0.059 \sim 0.238$ \\
\end{tabular}

TABLE 4 | Freundlich isotherm parameters for iodine adsorption over JLUE-COP-3.

\begin{tabular}{lllll}
\hline Freundlich isotherm & Temperature (K) & $\boldsymbol{K}_{\boldsymbol{F}}$ & $\boldsymbol{R}^{\mathbf{2}}$ & $\mathbf{1 / n}$ \\
\hline F & $288 \mathrm{~K}$ & 23.79 & 0.98 & 0.36 \\
& $298 \mathrm{~K}$ & 25.62 & 0.98 & 0.36 \\
& $308 \mathrm{~K}$ & 26.40 & 0.98 & 0.37 \\
\hline
\end{tabular}

electron acceptor, might improve the enrichment of iodine (Lin L. et al., 2017). As shown in Figure 4D, the curves of intraparticle diffusion model could be roughly divided into two stages. The two linear lines indicated the iodine diffusion from solutions to the surfaces of JLUE-COP-3 and the slow intraparticle diffusion into pores exist side by side (Table 2) (Li et al., 2012).

To understand in depth the adsorption machine-processed and acquire the maximum adsorption capacity of iodine over the JLUE-COP-3, a battery of experiments were studied under three temperature gradients of 288,298 , and $308 \mathrm{~K}$ with five concentration gradients of $50-250 \mathrm{mg} / \mathrm{L}$. The two widespreadly used models go by the name of Langmuir isotherm and Freundlich isotherm, are used to analyze the homogenous monolayer adsorption process and the heterogeneous multilayer adsorption, respectively, can be represented as following equations (Langmuir, 1918; Freundlich and Heller, 1939):

$$
\begin{array}{r}
\frac{C_{e}}{q_{e}}=\frac{1}{K_{L}}+\frac{a_{L} C_{e}}{K_{L}} \\
\ln q_{e}=\ln K_{F}+\frac{1}{n} \ln C_{e}
\end{array}
$$

Where $q_{e}$ is the equilibrium adsorption amount $(\mathrm{mg} / \mathrm{g}), C_{e}$ is the equilibrium iodine concentration $(\mathrm{mg} / \mathrm{L}), Q_{m}$ is the maximum adsorption capacity $(\mathrm{mg} / \mathrm{g}), K_{L}$ and $a_{L}, K_{F}$ and $n$, are the Langmuir and Freundlich adsorption isotherm constants, respectively.

The evolution of iodine adsorption process of JLUE-COP-3 interpreted by the Langmuir and Freundlich models are clearly shown in Figures 5A-C. The derived parameters in respect to the two models are included in Tables 3, 4, respectively. Likewise, in accordance to the linear correlation coefficient values of $R^{2}$, the Langmuir adsorption isotherm model describes the iodine adsorption process of JLUE-COP-3 well. In terms of the L-type shape of the isotherms on the basis of proposes by Giles et al. (1960), the monolayer iodine adsorption over JLUE-COP-3 was given weight. The initial nearly vertical part of the isotherms,

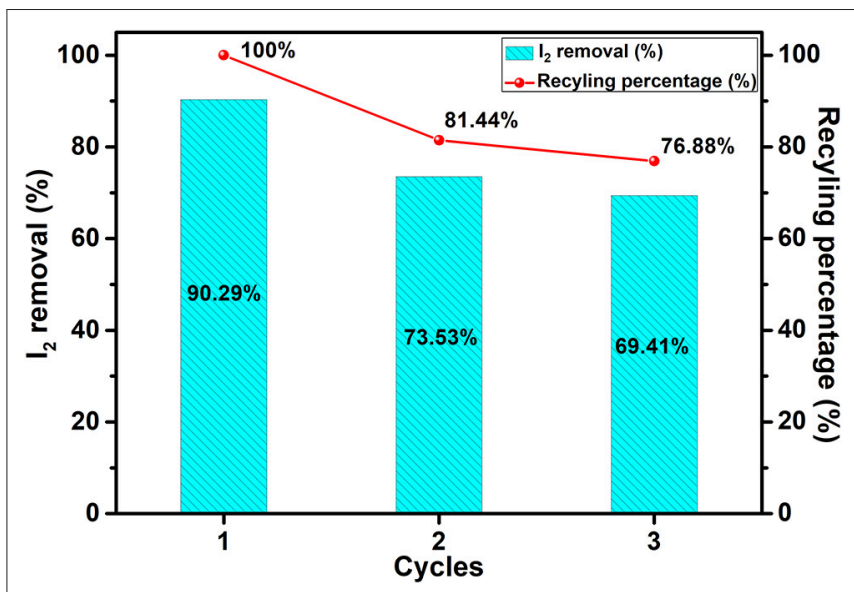

FIGURE 6 | Recycling results of iodine adsorption over JLUE-COP-3.

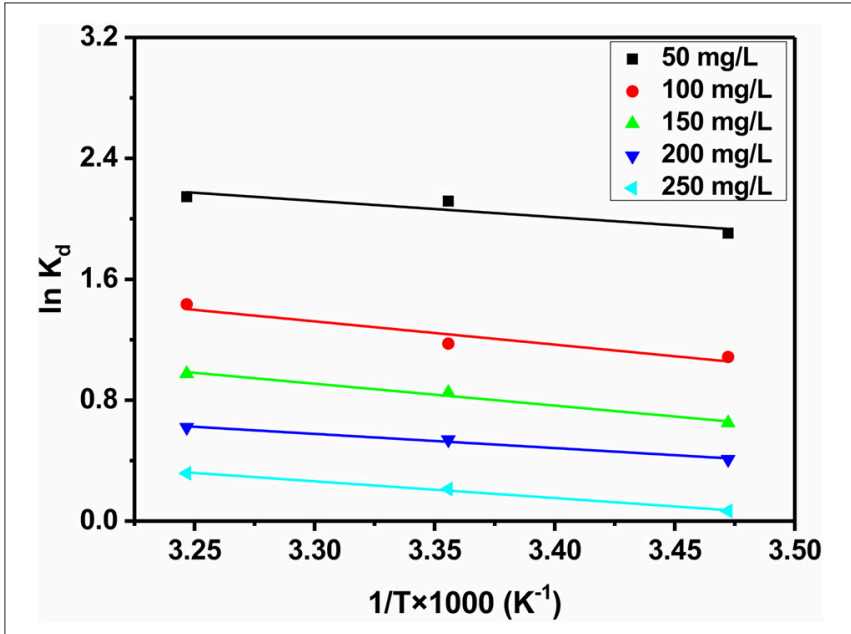

FIGURE 7 | Van't Hoff plots of iodine adsorption over JLUE-COP-3.

indicated the high host-guest affinity at lower concentrations. In addition, the maximum adsorption capacities $\left(Q_{m}\right)$ of iodine over JLUE-COP-3 were calculated to be $142.86,153.85$, and 158.73 $\mathrm{mg} / \mathrm{g}$ at 288,298 , and $308 \mathrm{~K}$, respectively.

The recyclability and durability of the JLUE-COP-3 toward iodine were evaluated for exploring the practical value. The adsorbents were generated as previously reported for the subsequent adsorption cycles (Wang et al., 2017). The results in Figure 6 demonstrated that after three recycles, the recycling percentage of iodine was still commendable (maintained $76.8 \%$ of the initial capacity and with a removal efficiency of $69.4 \%$ at $100 \mathrm{mg} / \mathrm{L}$ ), which could be on a par of UiO-66-PYDC (Wang et al., 2017), demonstrating the good repeatable and durable application of JLUE-COP-3 in treatment of iodine pollution.

Additionally, known as the equilibrium parameter, the separation factor " $R_{L}$ " can be used to judge the progression of the reaction using the following equation (Lu et al., 2009): 
TABLE 5 | Thermodynamic parameters of iodine adsorption over JLUE-COP-3.

\begin{tabular}{llllll}
\hline $\boldsymbol{C}_{\mathbf{0}}(\mathbf{m g} / \mathbf{L})$ & \multicolumn{3}{c}{$\boldsymbol{\Delta \boldsymbol { G } ^ { \circ } { } ^ { \circ } ( \mathrm { KJ } / \mathbf { m o l } )}$} & $\begin{array}{c}\boldsymbol{\Delta} \boldsymbol{H}^{\circ} \\
(\mathbf{K J} / \mathbf{m o l})\end{array}$ & $\begin{array}{c}\boldsymbol{\Delta} \boldsymbol{S}^{\circ} \\
(\mathbf{K J} / \mathbf{m o l} / \mathbf{K})\end{array}$ \\
\cline { 2 - 4 } & $\mathbf{2 8 8 ~ K}$ & $\mathbf{2 9 8} \mathbf{K}$ & $\mathbf{3 0 8} \mathbf{K}$ & & \\
\hline 50 & -4.56 & -5.07 & -5.14 & 21.42 & 0.11 \\
100 & -2.60 & -2.81 & -3.44 & 30.62 & 0.13 \\
150 & -1.55 & -2.03 & -2.33 & 28.79 & 0.11 \\
200 & -0.98 & -1.29 & -1.48 & 18.69 & 0.07 \\
250 & -0.16 & -0.51 & -0.76 & 22.05 & 0.08 \\
\hline
\end{tabular}

$$
R_{L}=\frac{1}{1+a_{L} C_{0}}
$$

Where $C_{0}$ is the initial iodine concentration $(\mathrm{mg} / \mathrm{L})$ and $a_{L}$ is the Langmuir binding constant $(\mathrm{L} / \mathrm{mg})$. The value of unit-less equilibrium parameter " $R_{L}$ " can be used to predict the shape of the adsorption isotherm: $\mathrm{R}_{\mathrm{L}}>1$ (unfavorable), $\mathrm{R}_{\mathrm{L}}=1$ (linear), 0 $<\mathrm{R}_{\mathrm{L}}<1$ (favorable) or $\mathrm{R}_{\mathrm{L}}=0$ (irreversible).

As shown in Figure 5D, the $R_{L}$ values for the iodine adsorption over JLUE-COP-3 at the temperatures of 288, 298, and $308 \mathrm{~K}$ were calculated to be in the ranges of $0.067-$ $0.265,0.065-0.257$ and $0.059-0.238$, respectively. These values alleged the favorable nature of iodine adsorption over JLUECOP-3. Moreover, the higher values of $R_{L}$ at the lower iodine concentration indicated that adsorption under the low concentration has more advantages than high concentration in this study.

For the sake of penetrating the mechanism of iodine adsorption over JLUE-COP-3, some basic thermodynamic parameters for the present system, such as Gibbs free energy $\Delta G^{\circ}$ $(\mathrm{KJ} / \mathrm{mol})$, enthalpy $\Delta H^{\circ}(\mathrm{KJ} / \mathrm{mol})$ and entropy $\Delta S^{\circ}(\mathrm{KJ} / \mathrm{mol} / \mathrm{K})$, were calculated using the following equations (Yao et al., 2012):

$$
\begin{array}{r}
K_{d}=\frac{q_{e}}{c_{e}} \\
\Delta G=-R T \ln \left(K_{d}\right) \\
\ln \left(K_{d}\right)=\frac{\Delta S}{R}-\frac{\Delta H}{R T}
\end{array}
$$

Where $K_{d}$ is the distribution coefficient $(\mathrm{L} / \mathrm{g}), R$ is the ideal gas constant $(8.314 \mathrm{~J} / \mathrm{mol} / \mathrm{K})$ and $T$ is the temperature in Kelvin $(\mathrm{K})$.

As summarized in Table 5, the calculated Gibbs free energy $\left(\Delta G^{\circ}\right)$ values were varied within the scopes of -4.56 to $-5.14,-2.60$ to $-3.44,-1.55$ to $-2.33,-0.98$ to -1.48 , and

\section{REFERENCES}

Ali, I. (2012). New generation adsorbents for water treatment. Chem. Rev. 112, 5073-5091. doi: 10.1021/cr300133d

Azadbakht, A., Abbasi, A. R., and Noori, N. (2016). Layer-by-layer synthesis of nanostructure NiBTC porous coordination polymer for iodine removal
-0.16 to $-0.76 \mathrm{KJ} / \mathrm{mol}$ at different initial iodine concentrations under three temperatures, respectively (Figure 7). Furthermore, the adsorption enthalpy $\left(\Delta H^{\circ}\right)$ and entropy $\left(\Delta S^{\circ}\right)$ for each concentration were determined to give the subsequent values of $21.42 \mathrm{KJ} / \mathrm{mol}$ and $0.11 \mathrm{KJ} / \mathrm{mol} / \mathrm{K}, 30.62 \mathrm{KJ} / \mathrm{mol}$ and 0.13 $\mathrm{KJ} / \mathrm{mol} / \mathrm{K}, 28.79 \mathrm{KJ} / \mathrm{mol}$ and $0.11 \mathrm{KJ} / \mathrm{mol} / \mathrm{K}, 18.69 \mathrm{KJ} / \mathrm{mol}$ and $0.07 \mathrm{KJ} / \mathrm{mol} / \mathrm{K}, 22.05 \mathrm{KJ} / \mathrm{mol}$ and $0.08 \mathrm{KJ} / \mathrm{mol} / \mathrm{K}$, respectively. In view of the negative values of $\Delta G^{\circ}$ and positive values of $\Delta H^{\circ}$ and $\Delta S^{\circ}$, which were regarded as basic criterions, the iodine adsorption over JLUE-COP-3 was sentenced to be spontaneous and endothermic (Kara et al., 2003; Yang Q. X. et al., 2017).

\section{CONCLUSION}

In summary, the JLUE-COP-3 polymer constructed through heterostructural mixed linkers was reasonably designed and successfully synthesized by a simple and high-speed Schiff base chemistry. The BTCH, BPDA and DABA were strategically employed as organic monomers for the construction of JLUECOP-3, simultaneously serving as active affinity sites for the efficient iodine removal. Owing to the porous specific, abundant $\pi$-conjugated phenyl rings and a great deal of functional $-\mathrm{CO}-$ $\mathrm{NH}-$ and $-\mathrm{SO}_{3} \mathrm{H}$ groups, JLUE-COP-3 polymer was proved to be a kind of good candidate for iodine capture and adsorption. In this study, the maximum adsorption capacity of JLUE-COP-3 was up to $153.85 \mathrm{mg} / \mathrm{g}$ at $298 \mathrm{~K}$. Additionally, the good recyclability and durability, prefiguring the great promise of JLUE-COP3 for the actually applying in nuclear waste management. In consideration of the strong affinity to iodine, the easy-obtained and low-priced JLUE-COP-3 polymer could be potentially used in chromatographic column analysis for strengthening the iodine retention.

\section{AUTHOR CONTRIBUTIONS}

YL and DZ conceived and designed the experiments, interpreted the results, and drafted the manuscript. HG, HY, and ML performed the experiments. ZL, FX, and WS analyzed the data. All authors have given approval to the final version of the manuscript.

\section{FUNDING}

This work was supported by the National Natural Science Foundation of China (Project No. 41572214 and 41772241), Special Project of Jilin Provincial School Construction Project (SXGJXX2017-9), Graduate Innovation Fund of Jilin University and the 111 Project (B16020). from wastewater. J. Inorg. Organomet. Polym. Mater. 26, 479-487. doi: 10.1007/s10904-016-0332-8

Calik, M., Sick, T., Dogru, M., Döblinger, M., Datz, S., and Budde, H., et al. (2016). From highly crystalline to outer surface-functionalized covalent organic frameworks-a modulation approach. J. Am. Chem. Soc. 138, 1234-1239. doi: $10.1021 /$ jacs.5b10708 
Chen, X., Addicoat, M., Jin, E. Q., Xu, H., Hayashi, T., Xu, F., et al. (2015). Designed synthesis of double-stage two-dimensional covalent organic frameworks. Sci. Rep. 5:14650. doi: 10.1038/srep14650

Dimos, K., Arcudi, F., Kouloumpis, A., Koutselas, I. B., Rudolf, P., Gournis, D., et al. (2017). Top-down and bottom-up approaches to transparent, flexible and luminescent nitrogen-doped carbon nanodot-clay hybrid films. Nanoscale 9, 10256-10262. doi: 10.1039/C7NR02673K

Ding, S. Y., Dong, M., Wang, Y. W., Chen, Y. T., Wang, H. Z., Su, C. Y., et al. (2016). Thioether-based fluorescent covalent organic framework for selective detection and facile removal of mercury(II). J. Am. Chem. Soc. 138, 3031-3037. doi: $10.1021 /$ jacs.5b10754

Dong, J., Xu, F. F., Dong, Z. J., Zhao, Y. S., Yan, Y., Jin, H., et al. (2018). Fabrication of two dual-functionalized covalent organic polymers through heterostructural mixed linkers and their use as cationic dye adsorbents. RSC Adv. 8, 19075-19084. doi: 10.1039/C8RA01968A

Duan, J. M., and Su, B. (2014). Removal characteristics of Cd(II) from acidic aqueous solution by modified steel-making slag. Chem. Eng. J. 246, 160-167. doi: 10.1016/j.cej.2014.02.056

Duan, S. X., Tang, R. F., Xue, Z. C., Zhang, X. X., Zhao, Y. Y., Zhang, W., et al. (2015). Effective removal of $\mathrm{Pb}(\mathrm{II})$ using magnetic $\mathrm{Co}_{0.6} \mathrm{Fe}_{2.4} \mathrm{O}_{4}$ micro-particles as the adsorbent: synthesis and study on the kinetic and thermodynamic behaviors for its adsorption. Colloids Surf. A 469, 211-223. doi: 10.1016/j.colsurfa.2015.01.029

Freundlich, H., and Heller, W. (1939). The adsorption of cis- and transazobenzene. J. Am. Chem. Soc. 61, 2228-2230. doi: 10.1021/ja01877a071

Giles, C. H., MacEwan, T. H., Nakhwa, S. N., and Smith, D. (1960). Studies in adsorption Part XI: A system of classification of solution adsorption isotherms, and its use in diagnosis of adsorption mechanisms and in measurement of specific surface areas of solids. J. Chem. Soc. 3973-3993. doi: 10.1039/JR9600003973

Guo, Z. H., Wang, C. X., Zhang, Q., Che, S., Zhou, H. C., and Fang, L. (2018). Cost-effective synthesis and solution processing of porous polymer networks through methanesulfonic acid-mediated aldol triple condensation. Mater. Chem. Front. 2, 396-401. doi: 10.1039/C7QM00485K

Hasell, T., Schmidtmann, M., and Cooper, A. I. (2011). Molecular doping of porous organic cages. J. Am. Chem. Soc. 133, 14920-14923. doi: 10.1021/ja205969q

Ho, Y. S., and McKay, G. (1999). Pseudo-second order model for sorption processes. Process Biochem. 34, 451-465. doi: 10.1016/S0032-9592(98)00112-5

Huang, N., Zhai, L., Xu, H., and Jiang, D. (2017). Stable covalent organic frameworks for exceptional mercury removal from aqueous solutions. J. Am. Chem. Soc. 139, 2428-2434. doi: 10.1021/jacs.6b12328

Janeta, M., Bury, W., and Szafert, S. (2018). Porous silsesquioxane-imine frameworks as highly efficient adsorbents for cooperative iodine capture. ACS Appl. Mater. Interfaces 10, 19964-19973. doi: 10.1021/acsami.8b03023

Kara, M., Yuzer, H., Sabah, E., and Celik, M. S. (2003). Adsorption of cobalt from aqueous solutions onto sepiolite. Water Res. 37, 224-232. doi: 10.1016/S0043-1354(02)00265-8

Kosaka, K., Asami, M., Kobashigawa, N., Ohkubo, K., Terada, H., Kishida, N., et al. (2012). Removal of radioactive iodine and cesium in water purification processes after an explosion at a nuclear power plant due to the Great East Japan Earthquake. Water Res. 46, 4397-4404. doi: 10.1016/j.watres.2012.05.055

Langmuir, I. (1918). The adsorption of gases on plane surfaces of glass, mica and platinum. J. Am. Chem. Soc. 40, 1361-1403. doi: 10.1021/ja02242a004

Li, H., Ding, X. S., and Han, B. H. (2016). Porous azo-bridged porphyrinphthalocyanine network with high iodine capture capability. Chem. Eur. J. 22, 11863-11868. doi: 10.1002/chem.201602337

Li, Y., Du, Q., Liu, T., Sun, J., Jiao, Y., Xia, Y., et al. (2012). Equilibrium, kinetic and thermodynamic studies on the adsorption of phenol onto graphene. Mater. Res. Bull. 47, 1898-1904. doi: 10.1016/j.materresbull.2012.04.021

Liao, Y., Weber, J., Mills, B. M., Ren, Z., and Faul, C. F. J. (2016). Highly efficient and reversible iodine capture in hexaphenylbenzenebased conjugated microporous polymers. Macromolecules 49, 6322-6333. doi: 10.1021/acs.macromol.6b00901

Lin, L., Guan, H., Zou, D., Dong, Z., Liu, Z., Xu, F., et al. (2017). A pharmaceutical hydrogen-bonded covalent organic polymer for enrichment of volatile iodine. RSC Adv. 7, 54407-54415. doi: 10.1039/C7RA09414K

Lin, Y., Jiang, X., Kim, S. T., Alahakoon, S. B., Hou, X., Zhang, Z., et al. (2017). An elastic hydrogen-bonded cross-linked organic framework for effective iodine capture in water. J. Am. Chem. Soc. 139, 7172-7175. doi: 10.1021/jacs.7b03204
Lu, D. D., Cao, Q. L., Cao, X. J., and Luo, F. (2009). Removal of Pb(II) using the modified lawny grass: mechanism, kinetics, equilibrium and thermodynamic studies, J. Hazard. Mater. 166, 239-247. doi: 10.1016/j.jhazmat.2008. 11.018

Ma, H., Chen, J. J., Tan, L., Bu, J. H., Zhu, Y., Tan, B., et al. (2016). Nitrogen-rich triptycene-based porous polymer for gas storage and iodine enrichment. ACS Macro Lett. 5, 1039-1043. doi: 10.1021/acsmacrolett.6b00567

Merí-Bof,í, L., Royuela, S., Zamora, F., Ruiz-González, M. L., Segura, J. L., MunozOlivas, R., et al. (2017). Thiol grafted imine-based covalent organic frameworks for water remediation through selective removal of $\mathrm{Hg}(\mathrm{II})$. J. Mater. Chem. A 5 , 17973-17981. doi: 10.1039/c7ta05588a

Nguyen, V., and Grunwald, M. (2018). Microscopic origins of poor crystallinity in the synthesis of covalent organic framework COF-5. J. Am. Chem. Soc. 140, 3306-3311. doi: 10.1021/jacs.7b12529

Pang, Z. F., Xu, S. Q., Zhou, T. Y., Liang, R. R., Zhan, T. G., and Zhao, X. (2016). Construction of covalent organic frameworks bearing three different kinds of pores through the heterostructural mixed linker strategy. J. Am. Chem. Soc. 138, 4710-4713. doi: 10.1021/jacs.6b01244

Qian, X., Zhu, Z. Q., Sun, H. X., Ren, F., Mu, P., Liang, W. D., et al. (2016). Capture and reversible storage of volatile iodine by novel conjugated microporous polymers containing thiophene units. Acs Appl. Mater. Interfaces 8, 21063-21069. doi: 10.1021/acsami.6b06569

Sigen, A., Zhang, Y., Li, Z., Xia, H., Xue, M., Liu, X., et al. (2014). Highly efficient and reversible iodine capture using a metalloporphyrinbased conjugated microporous polymer. Chem. Commun. 50, 8495-8498. doi: 10.1039/C4CC01783H

Sun, Q., Aguila, B., and Ma, S. Q. (2017a). A bifunctional covalent organic framework as an efficient platform for cascade catalysis. Mater. Chem. Front. 1, 1310-1316. doi: 10.1039/C6QM00363J

Sun, Q., Aguila, B., Perman, J., Earl, L. D., Abney, C. W., Cheng, Y., et al. (2017b). Postsynthetically modified covalent organic frameworks for efficient and effective mercury removal. J. Am. Chem. Soc. 139, 2786-2793. doi: 10.1021/jacs.6b12885

Wang, Z., Huang, Y., Yang, J., Li, Y. S., Zhuang, Q. X., and Gu, J. L. (2017). The water-based synthesis of chemically stable Zr-based MOFs using pyridinecontaining ligands and their exceptionally high adsorption capacity for iodine. Dalton Trans. 46, 7412-7420. doi: 10.1039/c7dt01084b

Yang, H. S., Zhu, Y. L., Du, Y., Tan, D. Z., Jin, Y. H., and Zhang, W. (2017). Aromatic-rich hydrocarbon porous networks through alkyne metathesis. Mater. Chem. Front. 1, 1369-1372. doi: 10.1039/C6QM00359A

Yang, Q. X., Zhao, Q. Q., Ren, S. S., Chen, Z. J., and Zheng, H. G. (2017). Assembly of $\mathrm{Zr}-\mathrm{MOF}$ crystals onto magnetic beads as a highly adsorbent for recycling nitrophenol. Chem. Eng. J. 323, 74-83. doi: 10.1016/j.cej.2017.04.091

Yao, Y. J., Miao, S. D., Yu, S. M., Ma, L. P., Sun, H. Q., and Wang, S. B. (2012). Fabrication of $\mathrm{Fe}_{3} \mathrm{O}_{4} / \mathrm{SiO}_{2}$ core/shell nanoparticles attached to graphene oxide and its use as an adsorbent. J. Colloid Interface Sci. 379, 20-26. doi: 10.1016/j.jcis.2012.04.030

Yuan, Y. C., Sun, B., Cao, A. M., Wang, D., and Wan, L. J. (2018). Heterogeneous nucleation and growth of highly crystalline imine-linked covalent organic frameworks. Chem. Commun. 54, 5976-5979. doi: 10.1039/C8CC02381F

Zeng, Y. F., Zou, R. Y., Luo, Z., Zhang, H. C., Yao, X., Ma, X., et al. (2015). Covalent organic frameworks formed with two types of covalent bonds based on orthogonal reactions. J. Am. Chem. Soc. 137, 1020-1023. doi: 10.1021/ja510926w

Zhang, X. Y., Gu, P., Li, X. Y., and Zhang, G. H. (2017). Efficient adsorption of radioactive iodide ion from simulated wastewater by nano $\mathrm{Cu}_{2} \mathrm{O} / \mathrm{Cu}$ modified activated carbon. Chem. Eng. J. 322, 129-139. doi: 10.1016/j.cej.2017.03.102

Conflict of Interest Statement: The authors declare that the research was conducted in the absence of any commercial or financial relationships that could be construed as a potential conflict of interest.

Copyright $\odot 2019$ Guan, Zou, Yu, Liu, Liu, Sun, Xu and Li. This is an open-access article distributed under the terms of the Creative Commons Attribution License (CC $B Y)$. The use, distribution or reproduction in other forums is permitted, provided the original author(s) and the copyright owner(s) are credited and that the original publication in this journal is cited, in accordance with accepted academic practice. No use, distribution or reproduction is permitted which does not comply with these terms. 